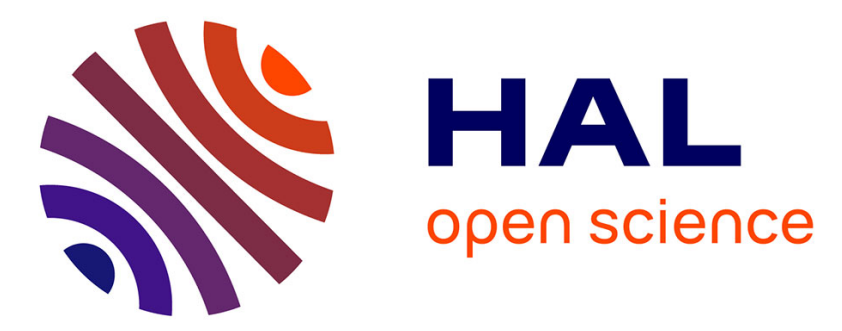

\title{
Optimization of tool geometry parameters for rotary peeling veneer process based on TLBO algorithm
}

Fatma, Zohra Bouarab, Hamid Aknouche, Abderrachid Hamrani

\section{To cite this version:}

Fatma, Zohra Bouarab, Hamid Aknouche, Abderrachid Hamrani. Optimization of tool geometry parameters for rotary peeling veneer process based on TLBO algorithm. CFM 2017 - 23ème Congrès Français de Mécanique, Aug 2017, Lille, France. hal-03465389

\section{HAL Id: hal-03465389 \\ https://hal.science/hal-03465389}

Submitted on 3 Dec 2021

HAL is a multi-disciplinary open access archive for the deposit and dissemination of scientific research documents, whether they are published or not. The documents may come from teaching and research institutions in France or abroad, or from public or private research centers.
L'archive ouverte pluridisciplinaire HAL, est destinée au dépôt et à la diffusion de documents scientifiques de niveau recherche, publiés ou non, émanant des établissements d'enseignement et de recherche français ou étrangers, des laboratoires publics ou privés. 


\title{
Optimization of tool geometry parameters for rotary peeling veneer process based on TLBO algorithm
}

\author{
F.Z BOUARAB ${ }^{\mathrm{a}}$, H .AKNOUCHE ${ }^{\mathrm{b}}$, A. HAMRANI ${ }^{\mathrm{c}}$,
}

a. Unité De Recherche Matériaux-Procédé et Environnement(MPRE), Université M'hamed Bougura Boumerdés (UMBB), Alegria, fz.bouarab@gmail.com.

b. Unité De Recherche Matériaux-Procédé et Environnement(MPRE), Université M'hamed Bougura Boumerdés (UMBB), Alegria, h.aknouche@yahoo.fr.

c. laboratoire énergétique mécanique (LEMI), Université M'hamed Bougura Boumerdés

(UMBB), Alegria, hamrani.abderrachid@gmail.com.

\section{Résume :}

Le déroulage est un des procédés singuliers de fabrication par enlèvement de matière dont la valeur ajoutée est apportée au copeau et non à la pièce, ce type d'usinage est une opération de coupe orthogonale du bois vert dont l'arête de coupe est parallèle à la fibre. L'objectif de notre travail les paramètres de coupe optimaux, géométrie de l'outil, a travers l'utilisation de la méthode TeachingLearning based optimization (TLBO) afin d'obtenir la meilleure qualité de la matière déroulée. Une étude théorique est menée pour l'identification la fonction objective qui caractérise le mieux les paramètres a optimisés. Le défit étant de maintenir la qualité de la matière déroulée toute en contrôlons la variation de l'épaisseur du plaquage et la condition de prés-fissuration. L'algorithme développé, implémenté sous MATLAB, est décrit suivant deux pseudo-code : l'algorithme principal de résolution et celui de la TLBO. Les résultats obtenus par la TLBO son en concordance avec les résultats expérimentaux. Le modèle numérique proposé nous permet de prédire les angles caractéristiques de l'outil pour différentes épaisseurs du plaquage et coefficients de frottement. La nécessité d'utiliser la barre de pression pour obtenir une bonne qualité de plaquage est numériquement prouvait

\footnotetext{
Abstract:

The development of economical and safer societies requires to improve the means of transport and of energy production. Rotating machines hold a central place. Rotary peeling veneer is a very specific machining process, where the chip is the final product. The fact that works related to this manufacturing process are rare, our objective is to investigate on the optimal cutting parameters, tool edge geometry, through the use of Teaching-Learning based optimization (TLBO) algorithm in order to obtain the best quality with the desired thickness of the veneer product. A study is carried out to identify the objective function that best characterize the machining parameters to be optimized. The challenge is to maintain the best possible quality of peeled veneer with the control of the pre-splitting condition and the veneer thickness variation. The developed algorithm, implemented in Matlab, used in this study is described through two pseudo-codes: main algorithm and the TLBO algorithm. In the main algorithm, the whole resolution procedure is prescribed. The second algorithm is dedicated to
} 
the description of all steps of the TLBO technique. Preliminary numerical results obtained from TLBO algorithm are consistent with the experimental ones. The proposed numerical model allows us to predict the characteristic tool angles for different chip thicknesses and friction coefficient. The need to use a pressure bar to produce a quality veneer is numerically proved.

\section{Mots clés: peeling veneer machining, teaching-learning based optimization, veneer thickness, tool geometry}

\section{Introduction}

Wood is the most widely used natural material in the manufacturing industry; it can be defined as an orthotropic material with specific chemical and physical properties [1]. The machining of wood products has acquired great importance in recent years, identified as being different from that for homogeneous metal removal in the need to avoid creating splintering, delaminating or burning. The various properties of the wood fiber and their orientations have a significant effect on the machining process [2]. The study of the wood machining process is around the chip formation, tool wear, work piece surface quality, crack initiation and propagation into the wood, with taking into account several factors such as humidity, temperature, and vibrations that can affect the wood during the machining process. There are three methods of cutting veneers, sawing, slicing/half round slicing, and rotary peeling is the most common [3]. The veneer is created by spinning the log and peeling off

a continuous sheet (figure 1). This is the least-expensive way to produce the veneer. Therefore, one of the big challenges is to maintain the best possible quality of peeled veneer, and this can be achieved with the control of the veneer thickness variation and the surface roughness. Optimum choice of the peeling veneer process parameters is primordial for the economic, efficient, and effective utilization of this particular wood machining process. Peeling veneer machining parameters are generally selected either based on the experience, and expertise of the operator. This way of working in most of the cases is unreliable, and selected machining parameters are far from the optimum. In recent years, soft computing and numerical techniques such as meta-heuristics optimization, fuzzy logic, experimental design method, artificial neural networks and other methods are gaining more attention from researchers dealing with manufacturing and machining processes. However, it is noticed that the lion's share of the researcher's attention is targeted towards metal cutting; very few works have been dedicated to wood cutting and even less on the optimization of the corresponding cutting parameters. The fact that works related to the peeling veneer process are extremely rare, our objective is to investigate on the optimal tool edge geometry of this process through the use of the meta-heuristic optimization algorithm : Teaching-Learning based Optimization (TLBO) algorithm, with the aim of obtaining the best quality with the desired thickness of the veneer product. A detailed study on the mechanics of the wood cutting process is carried Out through the definition of the geometry of the cutting tool and the corresponding cutting forces experienced during cutting, and the most important part about the chip deformation. The aim of this preliminary study is the Identification of the objective function that best characterize the machining parameters to be optimized. Numerical results obtained from TLBO algorithm are coherent with the experimental ones. The proposed numerical model allows us to predict the characteristic tool angles for different chip thicknesses and friction coefficients.

\section{Mechanics of the wood cutting process}


On the mechanics of cutting process, we are interested, in general, on defining the interactions between the cutting tool and the chip using the laws of engineering mechanics [4]. The mechanical properties of the material have to be taken into account: the anisotropy nature, the viscoelasticity and plastic properties of the wood. By the determination of the relationships between the forces and strains (deformations), then the cutting force depending on the properties of the material and the cutting tool, we can provide scientific bases to the phenomena of wood cutting.

\subsection{Characteristic angles and notations}

The geometry of the tool (angles of the edges) is one of the most important factors that effect the quality of machining products. In addition, the anisotropy and other material characteristics of wood have also a direct effect on the machining operation. The main cutting directions corresponding to the anisotropy are presented in figure $2[1,5]$.
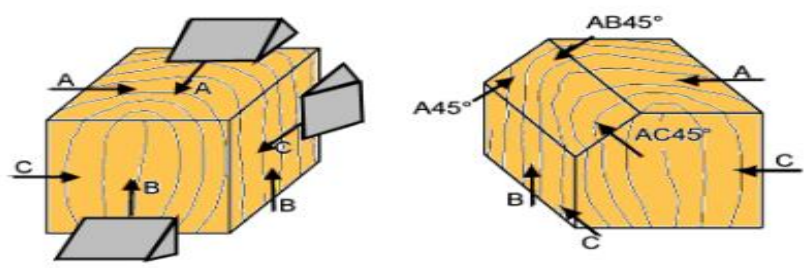

Figure 1: Main cutting directions and cutting corresponding to the anisotropy [5].
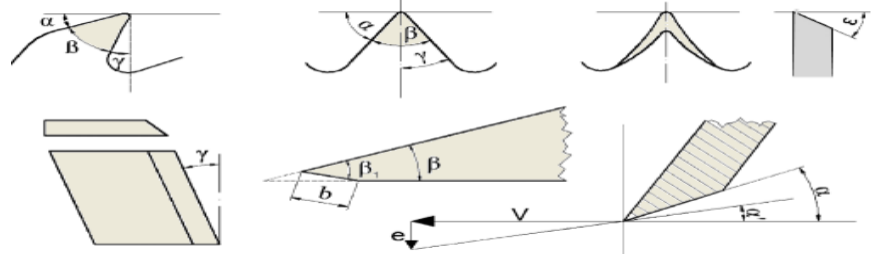

Figure 2: Characteristic angles of woodworking tools [5].

The characteristic angles of the wood machining tool are shown in figure 2 [5], we can quote:

$\alpha$ : Usually called "the clearance angle", it is generally $10^{\circ}-15^{\circ}$, but in the case of veneer cutting tool this angle is only around a $1^{\circ}$.

$\beta$ : Usually called "the sharpening or bevel angle"; in the case of veneer cutting knives, the angle values are around $20^{\circ}$

$\gamma$ : Usually called "the rake angle", which determines the chip deformation and is between $15^{\circ}$ and $25^{\circ}$, while for veneer cutting tools are around $70^{\circ}$

$\delta^{\prime}$ : Which is an oblique angle lowers the true cutting angle according to the following equation:

$$
\begin{aligned}
& \tan \delta^{\prime}=\tan \delta \cdot \cos \alpha . \\
& \delta=\alpha+\beta \ldots \ldots \ldots \ldots
\end{aligned}
$$

Where $\delta$ is "the cutting angle"

$\alpha^{\prime}$ : this angle is called "the moving clearance angle" occurs especially in peeling veneer and drilling due to the combination of the two effects of a circular and a linear feed motion :

$$
\tan \alpha^{\prime}=\frac{e}{v}
$$

Where $v$ the velocity of circular is motion and $e$ is the speed of linear motion.

$\beta_{1}$ : Usually called "back micro bevel angle" which is used in cutting veneer to avoid excessive wear of the tool edge having a small sharpening angle. 


\subsection{Cutting forces}

Forces experienced by a tool during cutting are detrimental in design of mechanical structure of cutting machine, predicting power consumption, determining the tool life and increasing the productivity. The experimental measurement of these cutting forces is a primordial tool allowing the development of mechanical cutting models for a better understanding of the phenomena observed during cutting. These models enable us to design or optimize processes, machines, tools and wood preparation [6]. Concerning the study of forces development during wood cutting, we can find several works treated by many authors $[7,8,9,10,11$, and 12]. The basic concepts related to the wood cutting forces are presented in the following.

Firstly, we have to suppose that the chip deforms on the knife's surface on a radius $R$, (figure 4). The normal force $N$ operate orthogonally on the tool's front surface, this force vector can be divided into two components: horizontal and vertical. When the chip slides on the knife's front surface, a frictional force $S=\mu N$ arise ( $\mu$ is the coefficient of friction at the tool-chip -work piece interface).

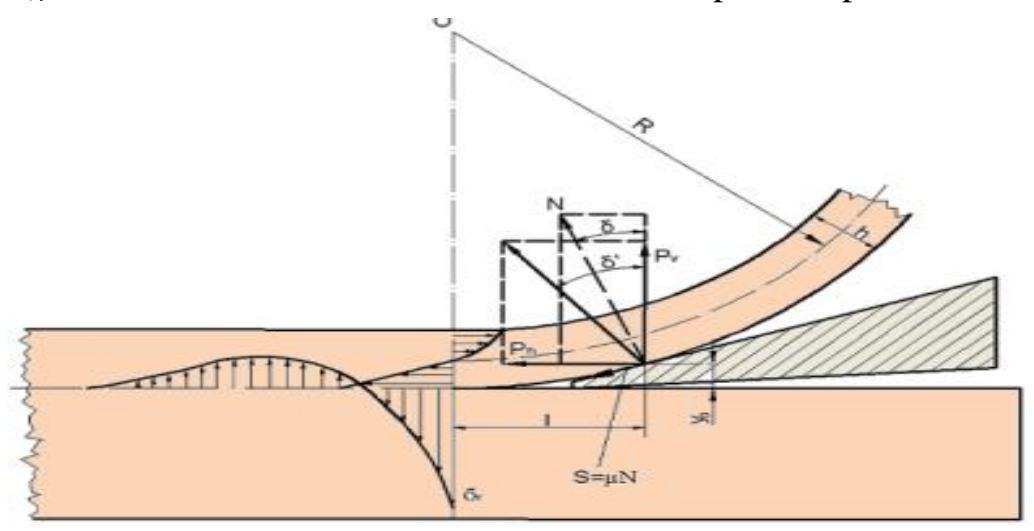

Figure 3: Force and stress relations of the chip [5].

The resultant force from the sum of the components shows an inclination towards the direction of the movement [1]. Its angle from the vertical will be given as follows:

$$
\begin{aligned}
& P_{h}=N \sin \delta+\mu N \cos \delta . \\
& P_{v}=N \cos \delta-\mu N \sin \delta .
\end{aligned}
$$

from which :

$$
\tan \delta^{\prime}=\frac{P_{h}}{P_{v}}=\frac{\tan \delta+\mu}{1-\mu \cdot \tan \delta}
$$

Where $P_{h}$ and $P_{v}$ are the horizontal and vertical cutting forces respectively. In the figure 3 (on the left side) the internal stress distributions are given. The stress distribution due to bending is asymmetric; the compression stress is near constant on the compressed side where the load on the material equals its strength. The result of the asymmetric stress distribution is that the neutral axis shifts to the tension side [1]. The stress distribution in front of the cutting edge can be evaluated according to the following equation:

$$
\sigma_{z r}=k \cdot y
$$


Where: $k$ is the deformation modulus of the wood (determined approximately with an indenter), $y$ is the deformation occurs in a radial direction. The following correlation is given by the Boussinesqproblem [4]:

$$
p=\frac{4 E}{\pi\left(1-v^{2}\right)} \cdot \frac{y}{d}=k . y
$$

Where: $p$ is the pressure, $d \mathrm{~d}$ the diameter of the indenter, $E$ the modulus of elasticity and $v$ Poisson's ratio. For more details about Boussinesq-problem we refer the interested reader to the following references [13,14, and 15] the $k$ value depends on the diameter of the indenter according to equation 8 . The $\mathrm{y}$ deformation in a distance $\mathrm{x}$ from the edge of the knife can be calculated as:

$$
y=-\frac{P_{v} \cdot e^{-\beta . x}}{2 \beta E . I}[\cos \beta x+\beta \cdot l(\cos \beta x-\sin \beta x)]
$$

Where:

$$
\beta=\sqrt[4]{\frac{k}{4 E I}}
$$

Where:

$P_{v}$ The vertical force component.

I The moment of inertia of the chip.

$l$ The distance of the attack point of the $P_{v}$ force.

Using the above equations, the maximum tensile stress value is given from equations 8 and 9 as:

$$
\sigma_{z r \max }=\frac{k P_{v}(1+\beta .1)}{2 \beta^{3} \cdot E . I}
$$

The changing of radial deformation in the plane in front of the edge is illustrated on figure 5, we can observe that deformation in a given distance $\mathrm{x}$ changes from tensile to compressive field.

Finally, we determine the two components of the cutting force $\left(P_{v}\right.$ and $\left.P_{h}\right)$ as follow [1]:

$$
\begin{aligned}
P_{v} & =\frac{1}{f(\mu, \delta)} \cdot \frac{E \cdot \mathrm{b}}{50} \cdot\left(\frac{h}{R}\right)^{2} \cdot h \ldots \ldots \ldots . . . \\
P_{v} / b & =2 \rho \sigma_{c}+\frac{\tan \delta}{f(\mu, \delta)} \cdot \frac{E}{50} \cdot\left(\frac{h}{R}\right)^{2} \cdot \mathrm{h}
\end{aligned}
$$

Where:

$$
f(\mu, \delta)=\sin \delta(1-\mu \cdot \tan \delta)+\left(\sin \delta+x_{0} / R\right) \cdot \tan \delta \cdot(\tan \delta+\mu)
$$

$x_{0}$ : Geometrical pre-splitting (figure 8).

$b:$ Width of the chip,

$h$ : Thickness of the chip,

$\rho$ : The radius of the edge, 


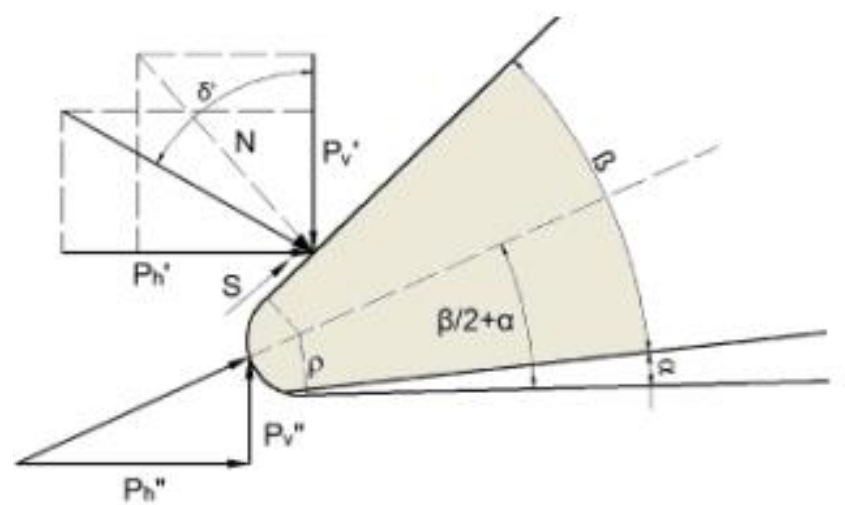

Figure 6: The position of the force acting on the edge [5].

We can write the vertical component of the whole resultant force acting on the tool as follows:

$$
P_{\text {vedge }} / b=2 \rho \sigma_{c} \sin (\beta / 2+\alpha)-\frac{B \cdot h}{\tan \delta}
$$

The horizontal component has the form:

$$
\begin{gathered}
P_{\text {hedge }} / b=2 \rho \sigma_{c}[\cos (\beta / 2+\alpha)+\mu \sin (\beta / 2+\alpha)]+\mathrm{B} . \mathrm{h} \\
\mathrm{B}=\frac{\tan \delta}{f(\mu, \delta)} \cdot \frac{E}{50} \cdot\left(\frac{h}{R}\right)
\end{gathered}
$$

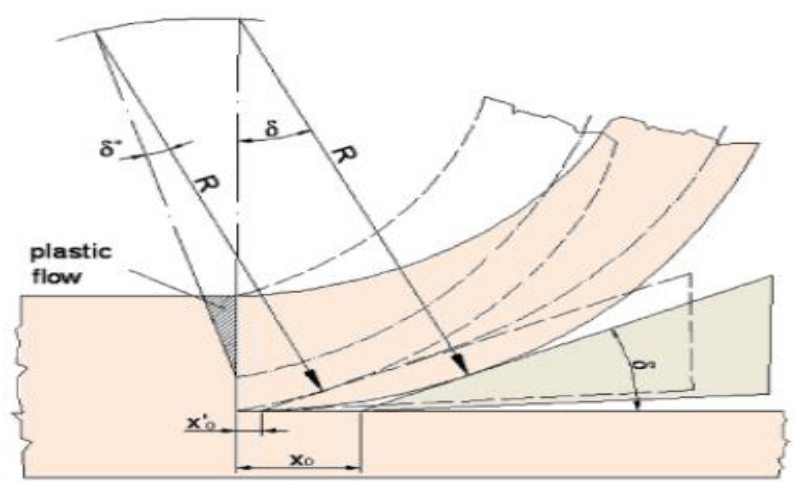

Figure 7: Plastic chip deformation [5].

The plot of the trigonometric function occurring in the second term of equation [13]: $\left(\tan \left(\delta^{\prime}\right) / f(\mu, \delta)\right)$ is illustrated in figure 9. In the interval of the angle $\delta$, we find that the trigonometric function have a parabolic shape with a minimum at about $\delta=40^{\circ}$, and that means that the cutting force is minimal in the given range. In the case of veneer cutting, $\delta$ is around $21^{\circ}$.

\subsection{Chip Deformation:}

As mentioned previously, the ratio $h / R$ is constant and known at a given $\delta$. But in reality, that is not totally true, because chip deformation has more than one degree of freedom, depending on the combined action of internal and external forces, and therefore, the $h / R$ ratio cannot be calculated from static equilibrium equations [1].

In order to determine the $h / R$ ratio, the minimum of potential energy principle may be used. To solve this problem, the virtual work produced by internal/external forces is described as follows: 


$$
\Delta\left(U_{i}+U_{e}\right)=0
$$

And

$$
U_{e}=-\sum F_{j} \delta_{y j}
$$

Where : $U_{i}, U_{e}$ are the work done by internal and external forces respectively, $\Delta$ symbol of variation, $F_{j}$ external forces, $\delta_{y j}$ virtual displacements.

The work done by internal forces in a bent beam is given by the following equation (Ritz method):

$$
U_{i}=\frac{1}{2} \int E \cdot I_{y^{\prime \prime}}^{2} d z=\frac{1}{4}\left(\frac{\pi}{2 l}\right)^{4} \cdot E \cdot I \cdot y^{2} \cdot l
$$

Where $I_{y^{\prime \prime}}^{2}$ means the curvature of the neutral axis . The work done by external forces is expressed in the following form:

$$
U_{e}=\frac{p_{h} \Delta l}{2}+\frac{p_{v} \cdot y_{0}}{2}
$$

In which the longitudinal deformation of the chip is given by

$$
\Delta l=\frac{P_{h} \Delta l}{E \cdot b \cdot h}
$$

Keeping in mind equation [6], the tangential and radial force components can be expressed using the bent beam theory:

$$
\begin{aligned}
& p_{h}=\frac{3 E I y_{0}}{l^{3}}(\tan \delta+\mu) \ldots \\
& p_{v}=\frac{3 E I y_{0}}{l^{3}}(1-\mu \tan \delta) .
\end{aligned}
$$

Taking the functional $\mathrm{F}=\mathrm{U}_{i}-\mathrm{U}_{e}$ and its derivative with respect to $\mathrm{y}$, setting the functional equal to zero, we get

$$
\frac{d F}{d y}=0
$$

Solving the above equation and using the $l \cong R \sin \delta$ approximation, the $h / R$ is given by the following equation:

$$
\frac{h}{R}=\frac{2 \sin \delta}{\sqrt{3}(\tan \delta+\mu)} \sqrt{\mu \tan \delta}
$$

In the above development we have supposed that the total bending work occurs in the elastic field and no plastic deformation occurs, but that is not the case. Beyond the yield limit, the bending forces remain constant and do no increase linearly with the deformation. Then we can add the following correction:

$$
\frac{h}{R}=\frac{2 \sin \delta}{\sqrt{3}(\tan \delta+\mu)} \sqrt{\mu \tan \delta} .
$$

Then

$$
h=R \frac{2 \sin \delta}{\sqrt{3}(\tan \delta+\mu)} \sqrt{(\mu \tan \delta)}
$$




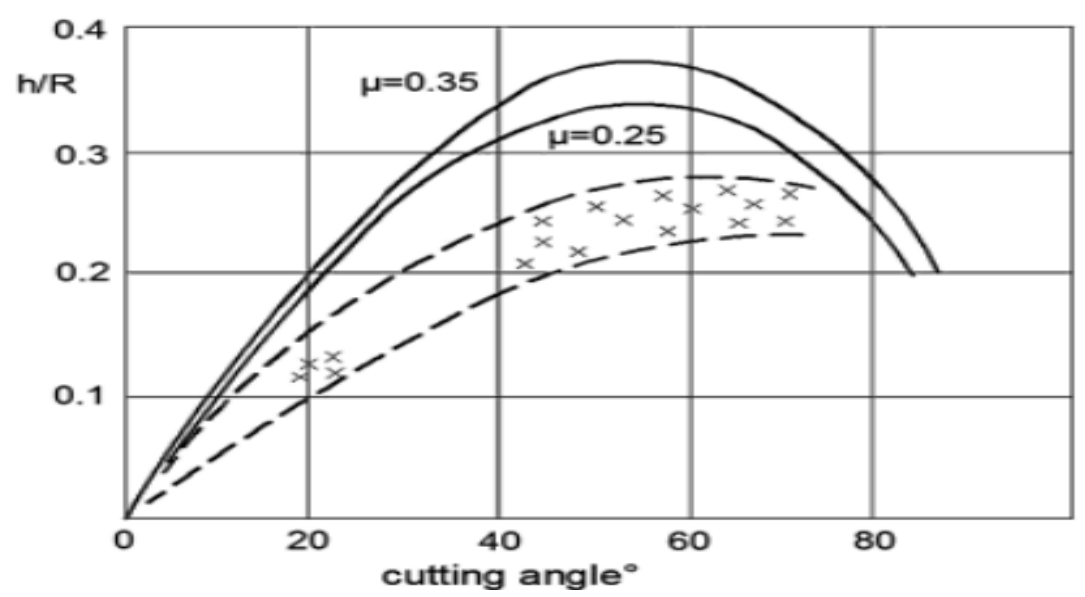

Figure 9: $\mathrm{h}=\mathrm{R}$ ratio as a function of cutting angle for two $\mu$ friction coefficients. (Dotted line is the boundary for measurement data) [5].

In figure 10, we observe that the values of the measuring results are systematically smaller than those obtained theoretically. This can be explained by the fact that the upper side of the chip yields plastically, and this leads to the rotation of the bent cross section, thus reducing the apparent value of the $\delta$ angle [1] (figure 7).

The values of material parameters for the wood specimen used in this study are listed in the following table:

\begin{tabular}{|l|l|l|l|l|l|}
\hline Wood species & Moisture & $\begin{array}{l}\text { Young's } \\
\text { modulus }\end{array}$ & $\begin{array}{l}\text { Deformation } \\
\text { modulus }\end{array}$ & $\begin{array}{l}\text { Compressive } \\
\text { strength }\end{array}$ & $\begin{array}{l}\text { Tensile } \\
\text { strength }\end{array}$ \\
\hline Red oak & $12 \%$ & $\begin{array}{l}\mathrm{E}=11,900 \\
\mathrm{MPa}\end{array}$ & $\begin{array}{l}\mathrm{k}=85000 \\
\mathrm{MPa}=\mathrm{mm}\end{array}$ & $\begin{array}{l}\sigma_{c} \\
=47000 \mathrm{Kpa}\end{array}$ & $\sigma_{t}=7200 \mathrm{KPa}$ \\
\hline
\end{tabular}

Table 1: Material parameters of the wood specimen.

\section{Optimization problem}

In this section, the optimization model of rotary peeling veneer process is formulated based on the above analysis. The optimization algorithm is carried out using a relatively recent heuristic search method, whose mechanics are inspired by works on the philosophy of teaching and learning, namely Teaching-Learning-Based Optimization (TLBO). A short presentation of the basics of this algorithm is described below

\subsection{Teaching-Learning based Optimization (TLBO) algorithm}

Teaching-learning-based optimization algorithm (TLBO) is a teaching-learning process inspired algorithm recently proposed by [29] based on the effect of influence of a teacher on the output of learners in a class. Teacher and learners are the two vital components of the algorithm and describes two basic modes of the learning, through teacher (known as teacher phase) and interacting with the other learners (known as learner phase). The output in TLBO algorithm is considered in terms of results or grades of the learners which depend on the quality of teacher. A high quality teacher is usually considered as a highly learned person who trains learners so that they can have better results in terms of their marks or grades. Moreover, learners also learn from the interaction among themselves which also helps in improving their results. The working of TLBO is divided into two parts, 'Teacher phase' and 'Learner phase'. Working of both the phase is explained below [32]. 


\section{1 .1 Teacher phase}

It is the first part of the algorithm where learners learn through the teacher. During this phase a teacher tries to increase the mean result of the class in the subject taught by him or her depending on his or her capability. At any iteration $i$, assume that there are' $m$ ' number of subjects (i.e., design parameters),' $n$ ' number of learners (i.e., population size, $k=1,2, \ldots \ldots \ldots, n$ ) and $M_{j, i}$ be the mean result of the learners in a particular subject $j$

( $j=1,2, \ldots ., m)$ the best overall result $X_{\text {total-kbest }, i}$, obtained in the entire population of learners considering all the subjects together can be considered as the result of best learner $K_{b e s t}$.

However, as the teacher is usually considered as a highly learned person who trains learners so that they can have better results, the best learner identified is considered as the teacher.

The difference between the existing mean result of each subject and the corresponding result of the teacher for each subject is given by:

$$
\text { difference_mean }{ }_{j, k, i}=r_{i}\left(\mathrm{X}_{j, k b e s t, i}-\mathrm{T}_{F} \mathrm{M}_{j, i}\right)
$$

Where, $\mathrm{X}_{j, k b e s t, i}$ is the result of the best learner (i.e., teacher) in subject $j, \mathrm{~T}_{F}$ is the teaching factor which decides the value of mean to be changed, and $r_{i}$ is the random number in the range $[0,1]$. The value of $\mathrm{T}_{F}$ is decided randomly with equal probability as:

$$
T_{F}=\operatorname{round}[1+\operatorname{rand}(0,1) 2-1]
$$

$T_{F}$ Is not a parameter of the TLBO algorithm. The value of $T_{F}$ is not given as an input to the algorithm and its value is randomly decided by the algorithm using Eq. (30). After conducting a number of experiments on many benchmark functions it is concluded that the algorithm performs better if its value is between 1 and 2, however, the algorithm is found to perform much better if the value of $T_{F}$ is either 1 or 2 and hence to simplify the algorithm, the teaching factor is suggested to take either 1 or 2 depending on the rounding up criteria given by Eq. (30). However, one can take any value of $T_{F}$ in between 1 and 2 .

Based on the Difference_Mean ${ }_{j, k, i}$ the existing solution is updated in the teacher phase according to the following expression.

$$
X_{j, k, i}^{\prime}=X_{j, k, i}+\text { Difference_Mean }
$$

Where $X_{j, k, i}^{\prime}$ is the updated value of $X_{j, k, i}$. Accept $X_{j, k, i}^{\prime}$ if it gives better function value.

All the accepted function values at the end of the teacher phase are maintained and these values become the input to the learner phase. [33]

\subsubsection{Learner phase}

It is the second part of the algorithm where learners increase their knowledge by interaction among themselves. A learner interacts randomly with other learners for enhancing his or her knowledge. A learner learns new things if the other learner has more knowledge than him or her. Considering a population size of ' $n$ ', the learning phenomenon of this phase is expressed below. Randomly select 
two learners $P$ and $Q$ such that $X_{\text {total }-P, i}^{\prime} \neq X_{\text {total }-Q, i}^{\prime}$ (where, $X_{\text {total }-P, i}^{\prime}$ and $X_{\text {total }-Q, i}^{\prime}$ are the updated values of $X_{\text {total }-P, i}$ and $X_{\text {total }-Q, i}$, respectively at the end of teacher phase).

$$
\begin{aligned}
& X_{j, P, i}^{\prime \prime}=X_{\mathrm{j}, P, i}^{\prime}+r_{i}\left(\mathrm{X}_{\mathrm{j}, P, i}^{\prime}-\mathrm{X}_{j, Q, i}^{\prime}\right), \quad \text { if } \quad X_{\text {total-P,i }}^{\prime} \prec X_{\text {total }-Q, i}^{\prime} \cdot \\
& X_{j, P, i}^{\prime \prime}=X_{\mathrm{j}, P, i}^{\prime}+r_{i}^{*}\left(\mathrm{X}_{\mathrm{j}, \mathrm{Q}, i}^{\prime}-\mathrm{X}_{j, \mathrm{P}, i}^{\prime}\right), \quad \text { if } \quad X_{\text {total }-Q, i}^{\prime} \prec X_{\text {total }-P, i}^{\prime}
\end{aligned}
$$

Accept $X_{j, P, i}^{\prime \prime}$, if it gives a better function value. All the accepted function values at the end of the learner phase are maintained and these values become the input to the teacher phase of the next iteration. The values of $r_{i}$ used in Eqs . (29), (32) and (33) can be different. The flow chart of TLBO algorithm is given in Figure (11) [33].

\subsection{Optimization model formulation}

\subsubsection{Objective function}

The mono-objective constrained optimization problem can be formulated, from equation (28), as follows:

$$
\left\{\begin{array}{l}
\min \left|\left(R \frac{2 \sin \delta}{\sqrt{3}(\tan \delta+\mu)} \sqrt{\mu \tan \delta}\right)-h\right| \\
\text { subjectto } \left.: \text { geometrocalpre }- \text { splitting } x_{0}=0 \text { (equalityconstraint }\right)
\end{array}\right.
$$

In this study, we envisage to optimize the cutting angle with fixing the veneer thickness between the range of $[0.1-3 \mathrm{~mm}]$ and give at each iteration a value of friction coefficient (table2)

\begin{tabular}{|l|l|l|l|}
\hline $\begin{array}{l}\text { cutting angle } \\
\delta\end{array}$ & $\begin{array}{l}\text { chip thickness } \\
h\end{array}$ & friction coefficients $\mu$ & $\begin{array}{l}\text { Radius } \\
R\end{array}$ \\
\hline $0^{\circ} \leq \delta \leq 85^{\circ}$ & $0.5 m m \leq h \leq 3 \mathrm{~mm}$ & $0.20 \leq \mu \leq 0.45$ & $5 \mathrm{~mm} \leq R \leq 200 \mathrm{~mm}$ \\
\hline
\end{tabular}

Table 2: Adopted search space parameters.

\section{Developed algorithm}

The developed algorithm, implemented in Matlab, used in this study is described through two flowcharts: main algorithm and the TLBO algorithm. In the main algorithm (figure 11), the whole procedure of the resolution is prescribed. The second algorithm (figure 12) is dedicated to the description of all steps of the TLBO technique.

The steps of the proposed optimizing process parameters of rotary veneer cutting operation using TLBO is given as follows:

- STEP 1: Define the optimization problem and initialize the optimization parameters

Initialize population size $\mathrm{N}=1000$

Number of generations $=100$

Number of design variables $=$ fixed $h$ and $\mu+\operatorname{random} \delta, \mathrm{R}$ 
Limits of design variables taken from table 2

Define optimization problem from equation 34

- STEP 2: Generate the population Initialize random population according to the population size (number of learners) and the number of design variables (the subjects).

- STEP 3: Teacher phase Compute the mean of the population to give the mean for the current subject.

- STEP 4: Learner phase Mutual interactions between learners enhance and increase their knowledge

- STEP 5: Termination criterion , Stop if the maximum generation number is achieved; otherwise repeat from STEP3.

\section{Results and discussion}

Figure 12 shows the fitness value of the best particle obtained whilst iterations runs. At the beginning, the fitness value is observed at the rate of 1 . When the iterative process reaches approximately 10 iterations, it is found that the value of fitness stabilize at zero. This observation confirm the convergence of the adopted TLBO algorithm

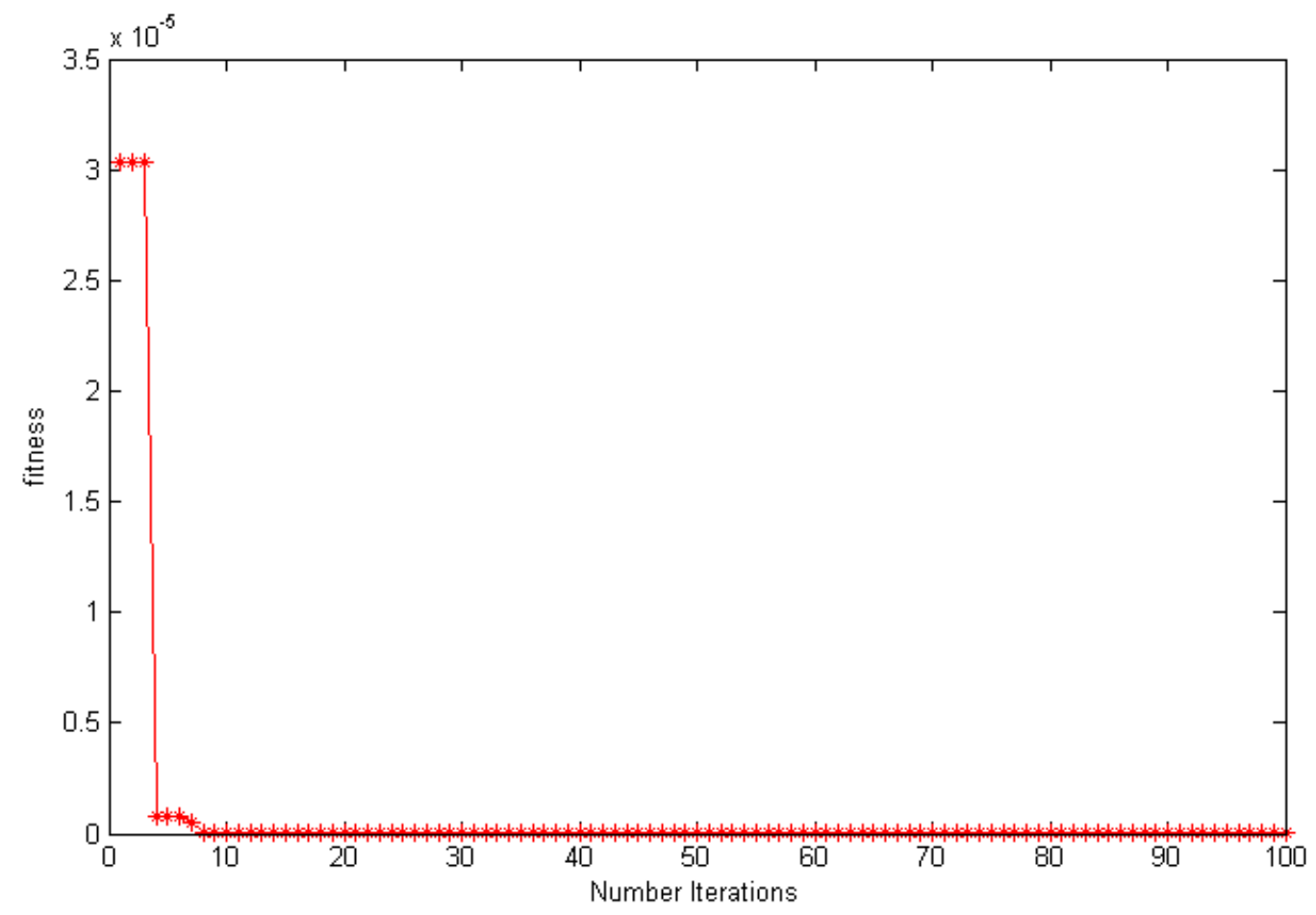

Figure 12: Performance of TLBO algorithm.

Figure 13 presents the values of $h / R$ ratio obtained from our TLBO code, as a function of the optimal parameter $\delta$, for different values of $\mu$ friction coefficients at the tool-chip-workpiece interface. 
Compared with the results obtained in figure 9, our results seem in good accordance and perform a prediction of the cutting angles $\delta$ and radius $\mathrm{R}$ for different values of friction coefficients $\mu$ and veneer thickness $h$. This observation confirms the fact that the adopted optimization model is valid.
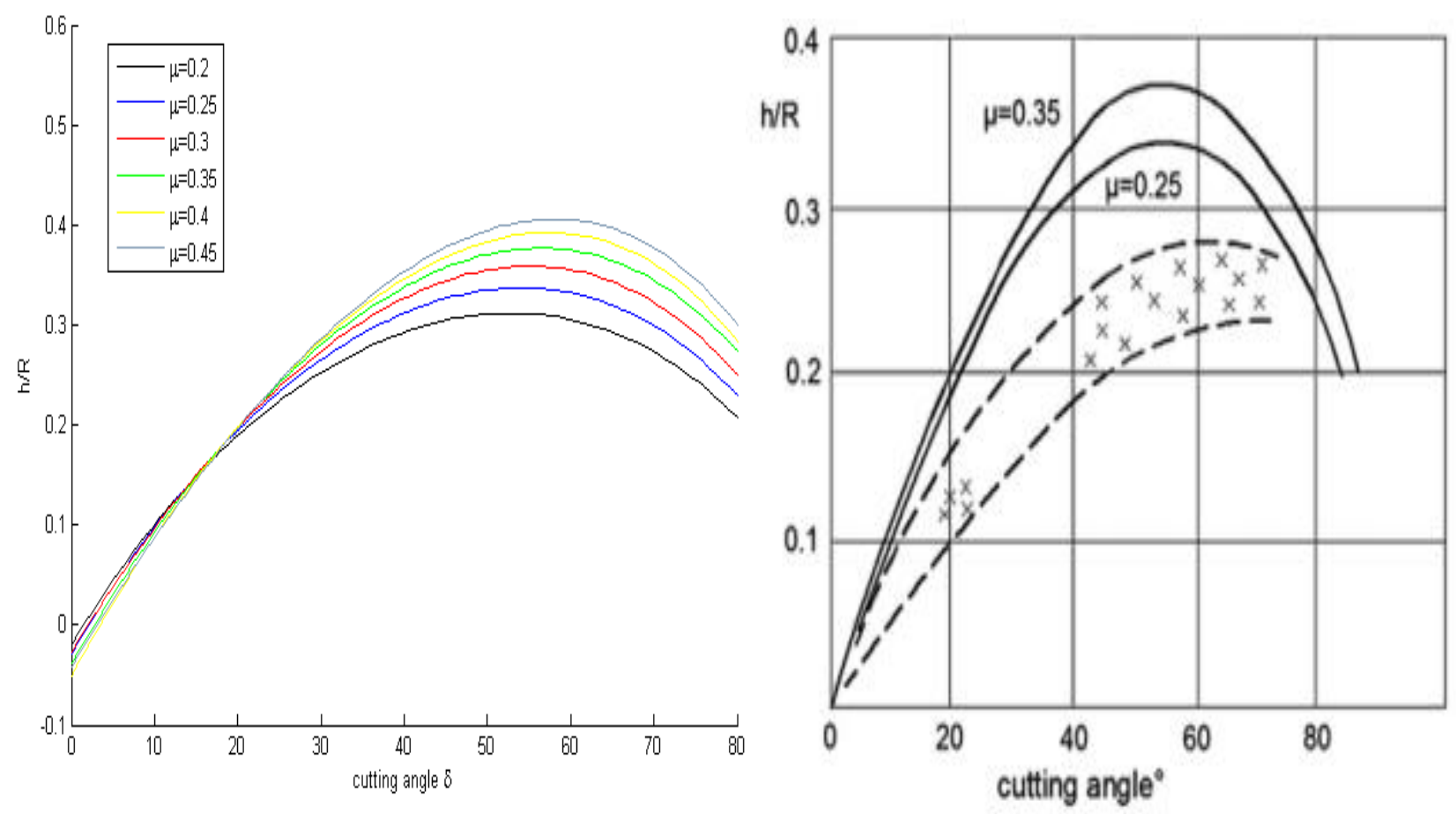

Figure 13: $h / R$ ratio as a function of cutting angle $\delta$ for different values of $\mu$ friction coefficients obtained from our TLBO code

After validating our numerical model, consideration has been given to the prediction of tool angle $\delta$ for different values of friction coefficients $\mu$ and veneer thickness $h$, in the particular case of rotary peeling veneer process. The assigned intervals for machining parameters are listed in table 4 .

\begin{tabular}{|c|c|c|c|}
\hline $\begin{array}{c}\text { cutting angle } \\
\delta\end{array}$ & $\begin{array}{c}\text { chip theckness } \\
h\end{array}$ & friction coefficients $\mu$ & radius $R$ \\
\hline $17^{\circ} \leq \delta \leq 27^{\circ}$ & $0.5 m m \leq h \leq 3 \mathrm{~mm}$ & $0.20 \leq \mu \leq 0.45$ & $5 \mathrm{~mm} \leq R \leq 200 \mathrm{~mm}$ \\
\hline
\end{tabular}

Table 4: Adopted search space parameters for rotary peeling veneer process

Figure 14 of the adopted TLBO algorithm, this is due to the fact that the objective function chosen in our study (equation 34) is conditioned by the pre-splitting restriction $\left(x_{0}=0\right)$. In practice, the use of small cutting angles is more inclined to cause pre-splitting, especially for production of chips (veneer) thicker than $2 \mathrm{~mm}$ [1]. Therefore, the use of a pressure bar is always essential to hamper pre-splitting. 


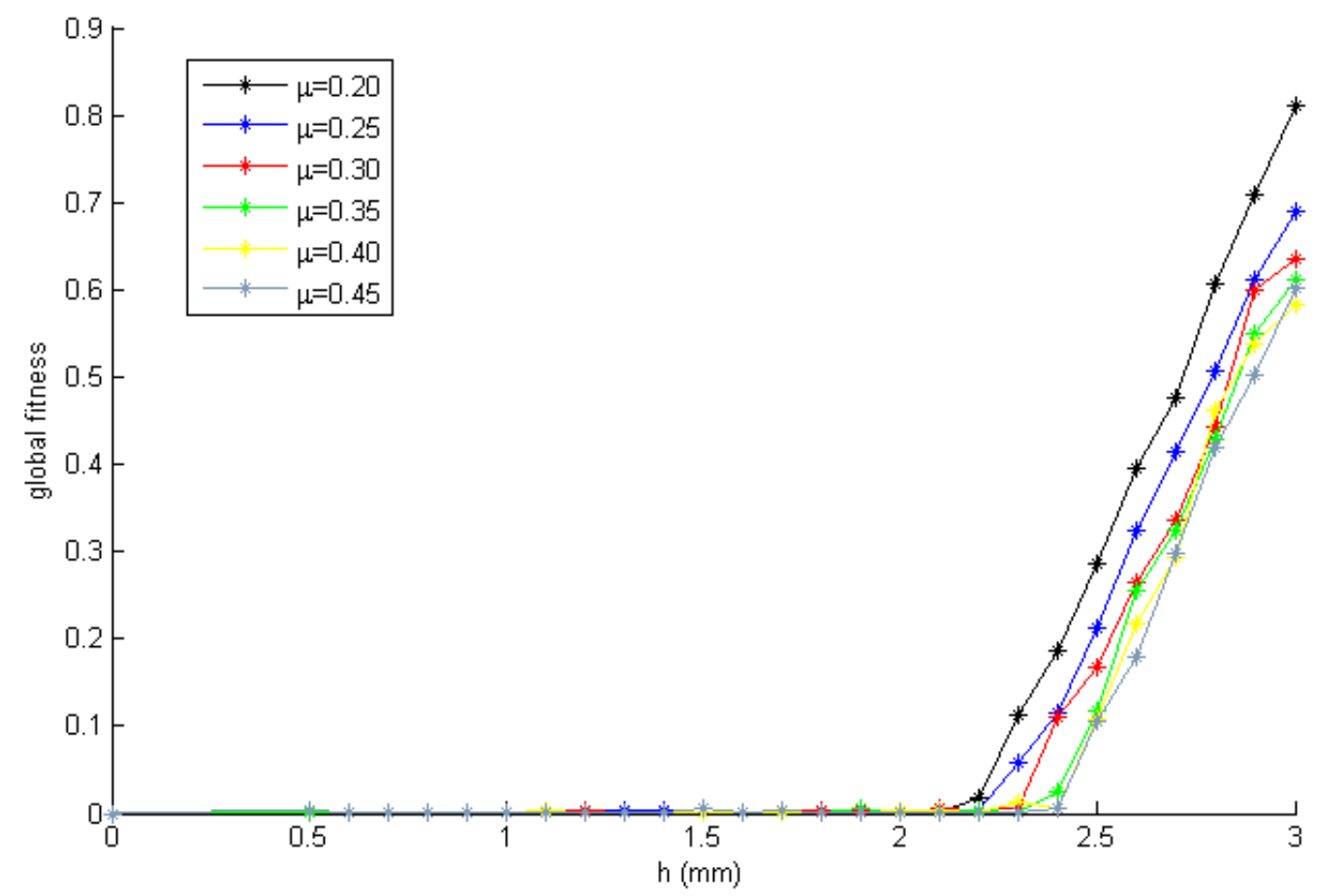

Figure 14: Global fitness as a function of thickness $\mathrm{h}$ for different values of $\mu$.

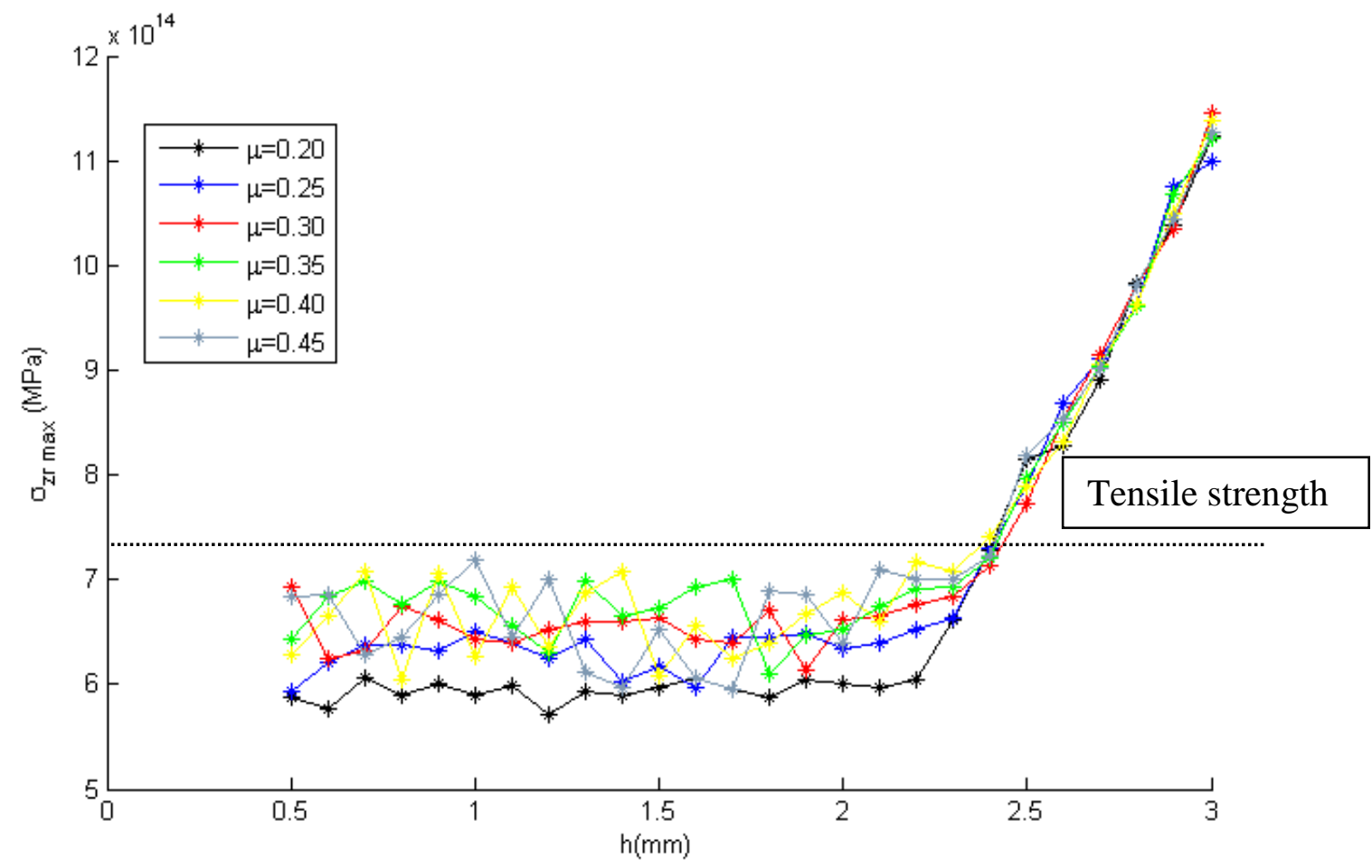

Figure 15: $\sigma_{z r \max }$ as a function of $\mathrm{h}$ for different values of friction coefficients $\mu$.

The final section is dedicated to the results of forces development during wood cutting in rotary peeling veneer process. The same observation can be made concerning the cutting forces, where the pre-splitting phenomenon is clearly apparent.

In figure 15, the condition of pre-splitting is verified for values of $\mathrm{h}$ greater than $2.5 \mathrm{~mm}$, where the maximum tensile stress value $\sigma_{z r \max }$ is larger than the tensile strength $\sigma_{t}$ of the wood. The variation 
of friction coefficient $\mu$ does not appear to have a significant effect on the maximum tensile stress value $\sigma_{z r \max }$.

The force components $P_{h_{\text {edge }}}$ and $P_{v_{\text {edge }}}$ for each cutting direction are shown in figures 16 and 17, respectively.

The tangential force $P_{h_{\text {edge }}}$ has positive values and increase with the increasing of veneer thickness $\mathrm{h}$. The radial force $P_{v_{\text {edge }}}$ has negative values and decrease with the increasing of veneer thickness $\mathrm{h}$. The variation of the two force components is intensified when the chip become thicker than $2 \mathrm{~mm}$. The effect of friction coefficient is more visible on the tangential force component compared to the radial one. This is due to the fact that friction force opposes motion between the two surfaces of tool and wood, and the most affected force component will be the one located along the tangent of tool feed direction.

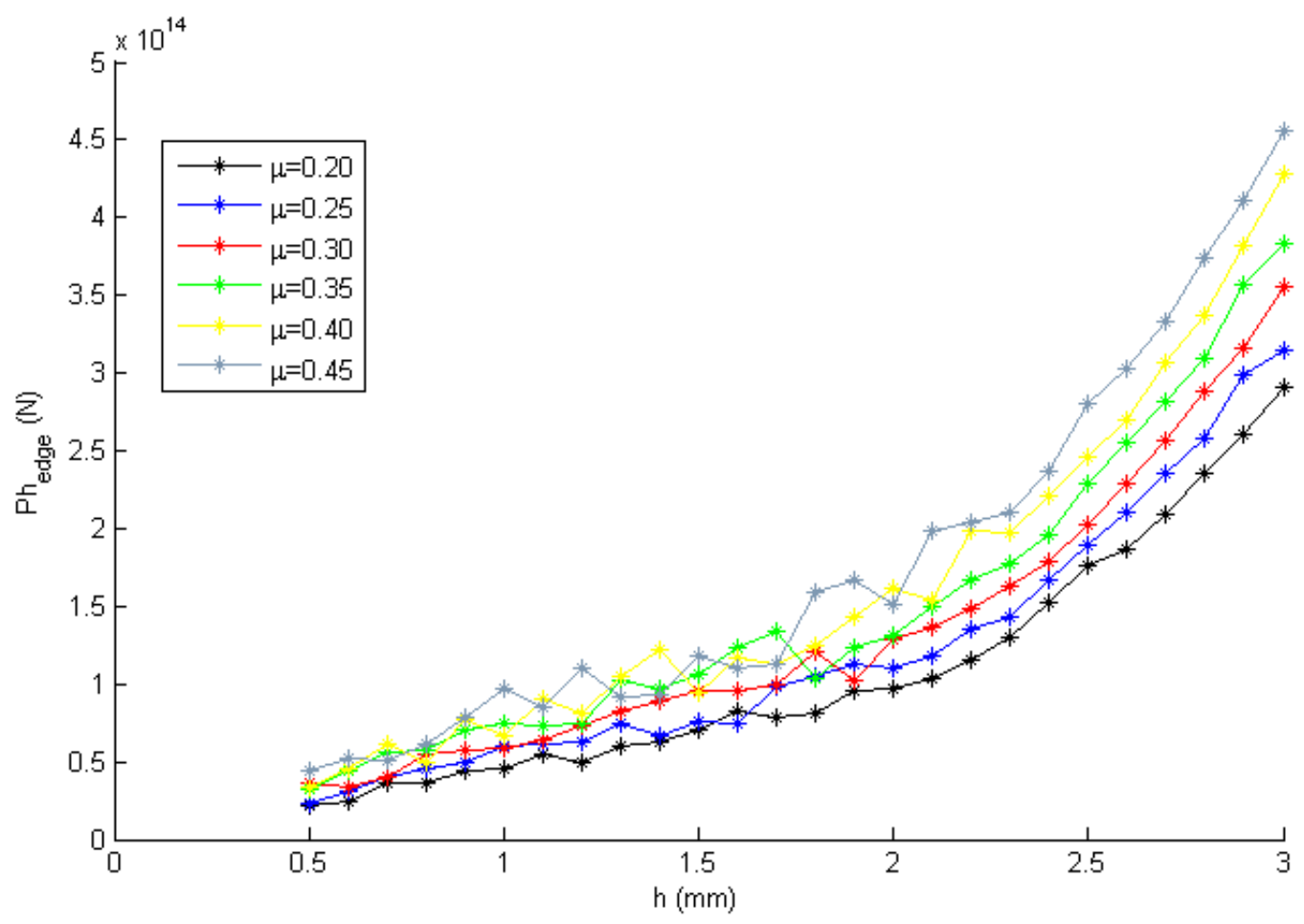

Figure 16: Variation of horizontal (tangential) cutting force $P_{h_{\text {edge }}}$ with varying chip thickness h for different values of $\mu$. 


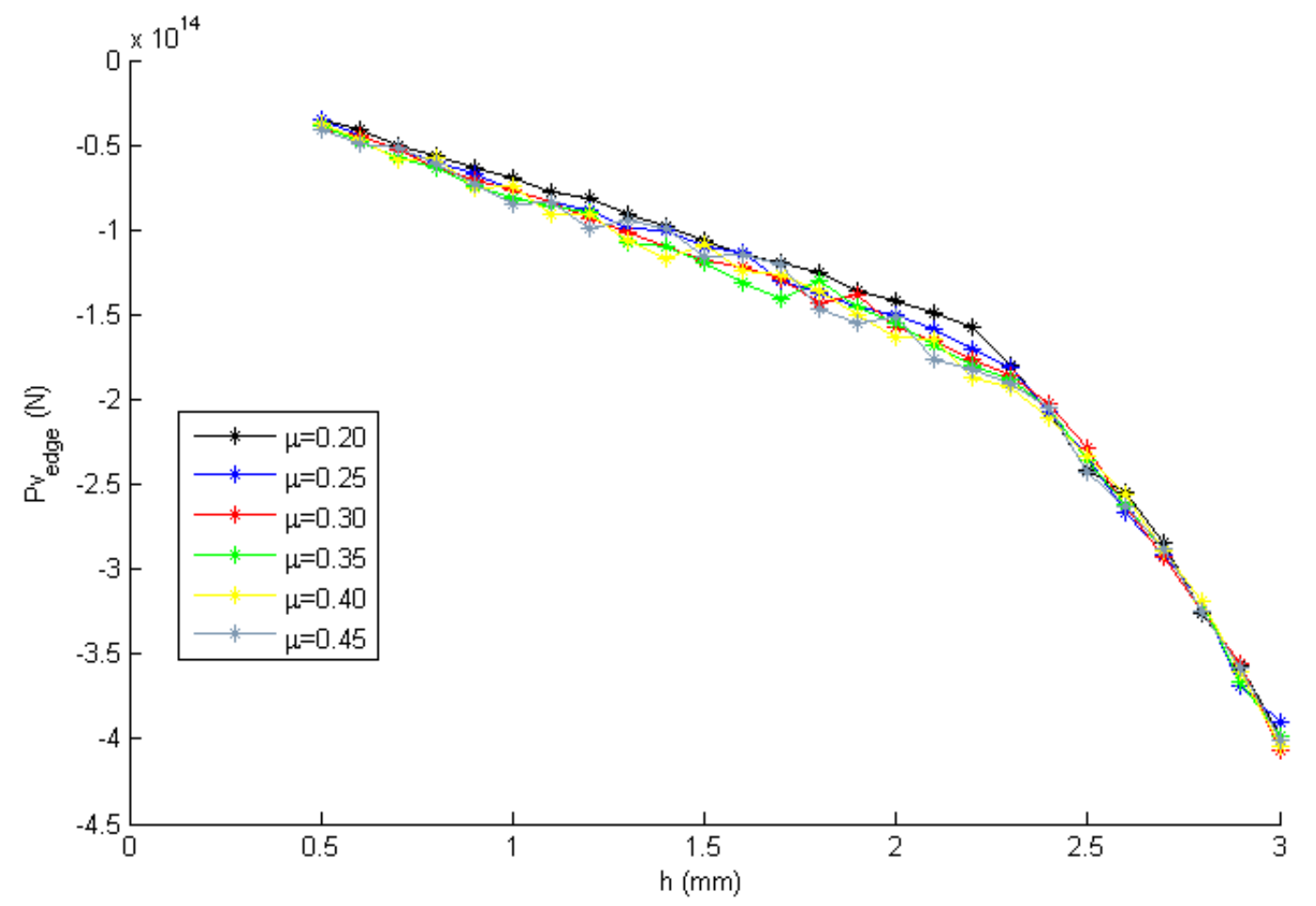

Figure 17: Variation of vertical (radial) cutting force $P_{v_{\text {edge }}}$ with varying chip thickness h for different values of $\mu$.

\section{Conclusion}

In this paper, a numerical study on the optimization of tool geometry parameters for rotary peeling veneer process has been conducted. The efficient Teaching-Learning Based Optimization (TLBO) approach has been adopted as an optimization technique. A theoretical and bibliographic review on the use of optimization techniques for wood cutting process has allowed us to support our argument that this work is the first of its kind. The proposed numerical model has been validated and tested for the prediction of the cutting angles in various machining situations (chip thicknesses, friction coefficients). The range of optimal cutting angles obtained from our numerical analysis is between 19 and 23, and for producing a thick wood veneer (thickness larger than $2 \mathrm{~mm}$ ) the use of a pressure bar is primordial to avoid pre-splitting and thus have a quality veneer product. This study deal with optimization on wood cutting process, and generates useful data for our future works (adding mechanics of pressure bar, application to wood slicing and milling processes, etc.) 


\section{Références}

[1] Etele Csandy and Endre Magoss. Mechanics of the cutting process. In Mechanics of Wood Machining, pages 1\{ 30. Springer Berlin Heidelberg, 2013. ISBN 978-3-642-29954-4.

[2] H Hocheng. Machining technology for composite materials principles and practice. Woodhead Pub, Philadelphia, Pa, 2012. ISBN 9780857090300.

[3] E Kirbach. Saw performance critical to lumber quality, yield. Wood Technol, 39:22\{24, 1995.

[4] Stephen Timoshenko and J. N. Goodier. Theory of elasticity. McGraw-Hill, New York, 1951.

[5] Theorie des Spanens von Holz : Mitteilungen von dem Lehrstuhl fur Holzbearbeitung.

Fortschrittberichte. EFE, 1990.

[6] Rémy Marchal, Frédéric Mothe, Louis-Etienne Denaud, Bernard Thibaut, and Laurent Bleron. Cutting forces in wood machining \{ basics and applications in industrial processes. a review cost action e35 2004\{2008: wood machining \{micromechanics and fracture. Holzforschung, 63(2): $157\{167,2009$.

[7] Peter Koch et al. Wood machining processes. Wood machining processes. 1964.

[8] Florent Eyma, Pierre-Jean Méausoone, and Patrick Martin. Study of the properties of thirteen tropical wood species to improve the prediction of cutting forces in mode $b$. Annals of forest science, 61(1) :55\{64, 2004.

[9] Florent Eyma, Pierre-Jean Méausoone, Pierre Larricq, and Rémy Marchal. Utilization of a dynamometric pendulum to estimate cutting forces involved during routing. Comparison with actual calculated values. Annals of forest science, 62(5) :441\{447, 2005.

[10] R Fischer and Ch Gottlober. Basics in the optimization of wood cutting in the example of peripheral milling. Proc 16th Int Wood Machin Sem, 2003.

[11] R Fischer. Micro processes at cutting edge \{some basics of machining wood, vienna. Proceedings of the $2^{\text {nd }}$ International Symposium on Wood Machining, pages 191\{202, 2004.

[12] Jan Palmqvist, Matz Lenner, and Stig-Inge Gustafsson. Cutting-forces when up-milling in beech. Wood science and technology, 39(8):674\{684, 2005.

[13] Ian N. Sneddon. The relation between load and penetration in the axisymmetric boussinesq problem for a punch of arbitrary profile. International Journal of Engineering Science, 3(1):47 \{ 57, 1965. ISSN 0020-7225. doi : http://dx.doi.org/10.1016/0020-7225(65)90019-4.

[14] N.A. Rostovtsev. On the theory of elasticity of a non homogeneous medium. Journal of Applied Mathematics and Mechanics, 28(4):745 \{ 757, 1964. ISSN 0021-8928.

doi : http://dx.doi.org/10.1016/0021-8928(64)90060-7.

[15] A.E. Giannakopoulos and S. Suresh. Indentation of solids with gradients in elastic properties: Part i. point force. International Journal of Solids and Structures, 34(19):2357\{ 2392 , 1997. ISSN 00207683. doi : http://dx.doi.org/10.1016/S0020-7683(96)00171-0.

[16] P Palanisamy, I Rajendran, and S Shanmugasundaram. Optimization of machining parameters using genetic algorithm and experimental validation for end-milling operations. The International Journal of Advanced Manufacturing Technology, 32(7):644\{655, 2007.

[17] R Saravanan and V Janakiraman. Study on reduction of machining time in cnc turning centre by genetic algorithm. In Conference on Computational Intelligence and Multimedia Applications, 2007. International Conference on, volume 1, pages 481\{486. IEEE, 2007\}.

[18] EJA Armarego, AJR Smith, and Jun Wang. Constrained optimization strategies and cam software for single pass peripheral milling. THE INTERNATIONAL JOURNAL OF PRODUCTION RESEARCH, 31(9):2139\{2160, 1993. 
[19] Kantheti Venkata Murali Krishnam Raju, Gink Ranga Janardhana, Podaralla Nanda Kumar, and Vanapalli Durga Prasada Rao. Optimization of cutting conditions for surface roughness in cnc end milling. International journal of precision engineering and manufacturing, 12(3):383\{391, 2011.

[20] V Tandon, H El-Mounayri, and H Kishawy. Nc end milling optimization using evolutionary computation. International Journal of Machine Tools and Manufacture, 42(5):595\{605, 2002.

[21] Jun Wang. Computer-aided economic optimization of end-milling operations. International Journal of Production Economics, 54(3):307\{320, 1998.

[22] J Wang and EJA Armarego. Computer-aided optimization of multiple constraints single pass face milling operations. Machining science and technology, 5(1):77\{99, 2001.

[23] ZG Wang, YS Wong, and M Rahman. Optimisation of multi-pass milling using genetic algorithm and genetic simulated annealing. The International Journal of Advanced Manufacturing Technology, 24(9-10) :727\{732,2004.

[24] Rao, R.V.,\& Kalyankar,V.D. (2013a). Parameter optimization of modern machining processes using teaching-learning-based optimization algorithm. Engineering Applications of Artificial Intelligence, 26(1), $524-531$

[25] Yildiz, A. R. (2013d). Optimization of multi-pass turning operations using hybrid teaching learning-based approach. International Journal of Advanced Manufacturing Technology, 66(9-12), 1319-1326.

[26] Rao, R. V., \& Kalyankar, V. D. (2012). Parameter optimization of modern machining processes using teaching-learning-based optimization algorithm. Engineering Applications of Artificial, 26(1), 524-531

[27] Togan, V. (2012). Design of planar steel frames using teaching-learning based optimization. Engineering Structures, 34, 225-232.

[28] Kunjie Yu · Xin Wang · Zhenlei Wang 2014 An improved teaching-learning-based optimization algorithm for numerical and engineering optimization problems DOI 10.1007/s10845-014-0918-3 [29] Rao, R. V., \& Patel, V. (2012). An elitist teaching-learning-based optimization algorithm for solving complex constrained optimization problem. International Journal of Industrial Engineering Computations, 3(4), 535-560.

[30] Sebahattin Tiryaki, Abdulkadir Malkocoglu, and Sukru Ozsahin. Using artificial neural networks for modeling surface roughness of wood in machining process. Construction and Building Materials, $66: 329\{335,2014$.

[31] Tomasz Gawronski. Optimization of CNC routing operations of wood en furniture parts. The International Journal of Advanced Manufacturing Technology, 67(9-12):2259\{2267, 2013.

[32] R. Venkata Rao*, V.D. Kalyankar, Multi-pass turning process parameter optimization using teaching-learning-based optimization algorithm, 2012

[33] R. V enkata Rao Vimal J.Savsani, Mechanical Design Optimization Using Advanced

Optimization Techniques, Springer Series in Advanced Manufacturing. 
